\title{
Citizen experiences of smart learning in China's cities
}

\author{
Rongxia Zhuang ${ }^{1}$, Sisi Tang ${ }^{2}$, Jihong $\mathrm{Li}^{1}$ and Ronghuai Huang ${ }^{1 *}$
}

\author{
* Correspondence: \\ huangrh@bnu.edu.cn \\ ${ }^{1}$ Smart Learning Institute of Beijing \\ Normal University, No. 12 Xueyuan \\ South Road, Haidian District, Beijing, \\ China \\ Full list of author information is \\ available at the end of the article
}

\begin{abstract}
Citizen learning experiences can be understood as their perceptions, responses, and performances to learning resources, learning approaches, in different fields in the city. This study aimed to analyze the characteristics of citizen learning experiences of smart learning in cities, as well as the influencing factors of citizen learning experiences. Data were collected through the telephone interview, and 13,600 individuals from 68 cities were involved. Pearson correlation analysis, crosstab analysis, and chi-square analysis were used to analyze the collected data. Findings revealed that there are strong correlations among learning engagement, learning approach, and learning achievement. However, there is a weak relationship between city's per-capita Gross Domestic Product (GDP) and learning engagement. Also, results showed that gender and age influence citizens' perceptions of learning experiences.

Keywords: Smart learning environments, Learning experience, Learning engagement, Learning approach, Learning achievement
\end{abstract}

\section{Background}

As cities are increasing continuously, the process of urbanization is a common trend across the globe and is faster in developing countries. Globally, 54\% of the world's population lives in urban areas in 2014, and the proportion will be $66 \%$ by 2050 . Africa (from $40 \%$ in 2014 to $56 \%$ by 2050 ) and Asia (from $48 \%$ in 2014 to $64 \%$ by 2050 ) are the continents, urbanizing faster than the other regions (United Nations, Department of Economic and Social Affairs, Population Division, 2015). The urban population of China was $11.18 \%$ in 1950 , more than $50 \%$ in 2011 , and up to $56.10 \%$ by 2015 (National Bureau of Statistics of the People's Republic of China, 2016). Kunzmann (2015) noted that enormous economic development in China had promoted the process of urbanization in the country. However, the rapid urbanization also creates problems such as rapid sprawl, pollution, and environmental degradation. These problems along with unsustainable production and consumption patterns threaten cities' sustainable development (United Nations, Department of Economic and Social Affairs, Population Division, 2015). The new Sustainable Development Goals regards people as one of the important themes (World Bank, 2016). United Nations appealed the education for sustainable development and sustainable lifestyles to ensure all learners acquiring the knowledge and skills of sustainable development (United Nation General Assembly, 2015).

(C) The Author(s). 2017 Open Access This article is distributed under the terms of the Creative Commons Attribution 4.0 International License (http://creativecommons.org/licenses/by/4.0/), which permits unrestricted use, distribution, and reproduction in any medium, provided you give appropriate credit to the original author(s) and the source, provide a link to the Creative Commons license, and indicate if changes were made. 
Integrating urban and digitalization, clean energy as well as other technologies, smart cities are being marketed across the world as solutions to the challenges of urbanization and sustainable development, they can provide options for inhabitants to make more ecofriendly choices, boost sustainable economic growth and enable cities to improve their service delivery (Datta, 2015; United Nations-Habitat, 2016). China's National New Urbanization Planning (2014-2020) put forward that smart city is one of the important developmental directions of China's urbanization. In the Dual-core framework of smart cities, proposed by Huang et al. $(2015, \mathrm{~b})$, the construction of smart cities on the micro level focuses on creating an environment livable for the citizens, and on the macro level focuses on creating an innovative developing environment, which are the two cores of smart cities' construction. The development of "smart learning" can play a cultural leading role for stimulating vitality for urban innovation, also provide scientific support for citizens' livable experiences (Huang et al., 2015, b).

Learning, as the fundamental issue for the development of individuals and societies, is a multifaceted reality defined by context (UNESCO, 2015a). Therefore, citizens' smart learning activities require the support of corresponding smart learning environments. In a smart learning environment, learners can learn at any time, any place, any way, and at any pace. Such learning environment can also support learners with the experience of easy, engaged and effective learning (Huang et al., 2015, b). Learning in smart cities improves the quality of life, equips citizens to anticipate and tackle new challenges, and help to build better and more sustainable societies (UNESCO, 2015b).

\section{Need for this study}

To understand the situation of people sustainable development in China's cities, especially to understand the support of smart cities for citizen's smart learning, this study investigated and analyzed characteristics of citizen's smart learning experiences in smart cities and identified relevant influencing factors. The specific questions addressed in this study are:

- Whether and to what extent the components of learning experiences are correlated to each other from the learners' point of view?

- Are there any relationships between city's economic development and citizens' perceptions of learning experiences?

- Are gender and age affecting factors for people's perceptions of learning experiences in smart learning environments?

\section{Theoretical background}

\section{User experience in a technology-rich learning environment}

Human experience is ongoing and varied. Researchers try to interpret experience from multiple perspectives (e.g., philosophical, psychological, social, etc.), but there is no uniform theory of human experience, and the spread of digital technologies is creating new experiences yet to be fully understood. In modern society, people can use various kinds of information technologies to support learning, which adds human-computer interaction to the complexity of understanding human learning experiences. From the perspective of human-computer interaction, people comprise the product-centric, user- 
centric, and interaction-centric experience analysis perspectives (Forlizzi \& Battarbee, 2004). Interaction is the focus of attention, and experience can be seen as a product of interaction processes. People interact with a certain object, and the interaction triggers a variety of factors involved in the experience. The interaction between people and the technologies in a learning environment includes three aspects: fluent, cognitive, and expressive humancomputer interaction, and forms three kinds of experiences: experience, an experience, and co-experience. Experience is the feeling and consciousness when we interact with products or environments; an experience is something that can be articulated or named; and coexperience is the user experience in social contexts, which creates meaning and emotion together through product use (Forlizzi \& Battarbee, 2004). It indicates that experience is both a process and a result, and involves behavior, cognition, as well as emotions and feelings.

In 1995, Norman et al. introduced the notion of user experience into the field of information design (Norman et al., 1995). Since then, researchers and developers have become more and more interested in user experience. However, they have not reached consensus on the nature and scope of user experience and its relationship to learning, decision making, and action. The notion of user experience extends from the obvious utility dimension (how the technology is used and what it makes possible) to including beauty, pleasure, and emotional experience associated with a technology-facilitated learning environment. Besides the instrumental dimensions, researches of user experience also cover users' needs, emotions, and the experience itself (Hassenzahl \& Tractinsky, 2006). Based on different understandings of the content and features of user experience, scholars have proposed a variety of models. The Basic User Experience Process and Research Framework proposed by Mahlke (2005), clearly shows the experience process when the user interacts with the interactive system, and also illustrates the relationship between interaction, cognition, emotion and follow-up actions. Based on this model, later sections of this study explain the connotation of learning experiences.

At present, the definition of 'user experience' given by ISO is widely recognized. In the ISO. 9241-210 standard, it is pointed out that "user experience is the cognition and response generated from the use of a product, system or service and/or expected use." This definition is close to the definition of learning experience that involves cognitive processing and subsequent responses. Learning experiences represent the user experience in the interaction with the educational product and the environment (Huang et al., 2015).

\section{Learning experiences of smart learning}

The learning experience is a notion derived from user experience and is also a kind of experience. The subject of a learning experience is the learner, just as the subject of a user experience is the user. Learning experiences can be understood as a variety of experiences through the learning process (see http://edglossary.org/learning-experience/). Based on the analysis of keywords from the domestic and foreign literatures on experience study, the study discovers that current research hotspots in respect of learning experiences include learning process, learning environment, learning outcomes, collaborative learning, students' learning, students' perceptions, online learning, and so on.

Obviously, researches on learning experiences still concentrate on the learning process and learning outcomes, related to environment, activities, groups, perception, interaction, and results, etc. Domestic studies focus on classroom teaching, independent 
learning, teaching effect, learning process, new curriculum, information technology, teaching method, MOOCs, teaching scenario, etc. Many domestic scholars are also concerned about these elements when defining learning experiences. $\mathrm{Hu}$ (2015) defined learning experiences as "learners' perception, reaction, and behavior of many factors involved in learning environment, learning activities and learning support services." This definition is supported by Feng et al. (2013) and Huang et al. (2015).

Basing on Combining Mahlke's user experience model, the ISO definition of user experience, and the above analysis of learning experiences, this study suggests that learning experiences can be understood as learners' perceptions, responses, and performances to the learning environment, resources, and methods. Gagné's information processing learning theory can be used to explain such a process. Gagné pointed out that the learner can perceive the information in the environment. After a series of information processes, the learner formed a unique cognition of such information and ultimately reacted with learner's response reactor (Gagne, 1985). Learners' perception of learning environment mainly refers to their perception of the people and the matters, including resources, tools, learning community, community education, learning styles, and teaching methods (Huang et al., 2012). Perception enables a person to carry out actions in the environment (Elnaga, 2012).

According to Mahlke's user experience model, learners' environment perceptions through interactions will deepen the cognitive process and change the feelings. All these perceptions will lead to corresponding follow-up actions, attitudes and emotional experiences. Response to a learning experience can include emotional reactions and behaviors.

Performance in this study mainly refers to the learner's behavior and associated benefits. It includes learning efficiency, effectiveness, achievement and etc. Learning efficiency and learning effects emphasize the low input and high output and gain lasting knowledge and skills. Learning achievement not only emphasizes the achievement of objective learning targets, but includes learning achievement, satisfaction and other related subjective experiences (Jia et al., 2013).

Based on such a conclusion, citizen learning experiences can be understood as their perceptions, responses, and performances to learning resources and learning approaches, in different fields in the city. Citizen learning experiences can also be ubiquitous, situation-dependent, dynamic, personalized, and group interactionoriented. Perception of typical fields of city learning environments is the basis of citizens' learning experiences. It can invoke behavioral and emotional reactions of the learners, and promote the formation of performance. Construction of learning environments cannot be finished without the support of city infrastructure, and a good learning experience is a target for the development of learning environments indeed.

According to the meaning of learning experiences, evaluation objectives and operability discussed above, the research and evaluation on learning environments in cities, conducted by the Smart Learning Institute of Beijing Normal University, begins from the perspective of citizens' learning experiences, from the overall perception, response, and performance of learning environments in the cities (Huang et al., 2016). It specially investigates citizens' perceptions and learning performances. The study believes that higher learning engagement degree, rich learning approach, and obvious learning achievements can greatly improve the citizens' 
learning experiences. Table 1 displays the evaluation indicators corresponding to citizens' learning experiences.

\section{Research method}

\section{Sample and data collection}

In this study, telephonic interview method was used to collect data. As parts of a 41item survey, eight questions were developed based on the indicators (see Table 1). The survey was designed to gain insight into citizens' perceptions towards smart learning environments in China cities. With random sampling and convenient sampling methods, a total of 13,600 valid samples from 68 cities (200 samples per city) were involved in this study. Table 2 shows the demographics of respondents.

\section{Data analysis}

Data were analyzed with SPSS Statistics 20.0. Based on the responses of citizens, various methods were used to calculate the indicator values of each city, such as ratio method, normalization using maximum value, equal-weight method, etc. Pearson correlations were computed to examine the intercorrelations among learning engagement, learning approach and learning achievement. Spearman rho statistics were calculated to investigate the relationship between indicators of citizen learning experiences and some influence factors, such as per capita GDP and so on. Crosstab analyses and Chi-square Tests of Independence were used to assess the associations between gender, age, and citizens learning experiences. A significance level of $p<0.05$ (2-tailed) was applied.

\section{Results}

\section{Correlation analyses}

\section{Correlation results among indicators of citizen learning experiences}

The descriptive statistical results (see Table 3) of citizen learning experiences showed that citizens from 68 cities have similar learning perceptions on learning achievement (mean value was high, and the coefficient of variation(CV) was low), while learning perception on learning approach differs greatly.

In Pearson correlation analyses, it was found that learning engagement indicator, learning approach indicator, and learning achievement indicator were pair-wise significantly correlated. The strongest positive correlation was between learning engagement

Table 1 Evaluation indicators of citizen experiences of smart learning

\begin{tabular}{|c|c|}
\hline Citizen learning experiences indicators & Evaluation indicators \\
\hline \multirow[t]{3}{*}{ Learning engagement indicator } & $\begin{array}{l}\text { Indicator of citizen's participation in learning } \\
\text { activities }\end{array}$ \\
\hline & Indicator of citizen reading \\
\hline & Indicator of citizen's daily studying time \\
\hline \multirow[t]{3}{*}{ Learning approach indicator } & Indicator of citizen's mobile learning \\
\hline & Indicator of citizen's self-regulated learning \\
\hline & $\begin{array}{l}\text { Indicator of utilization of city online learning } \\
\text { platform }\end{array}$ \\
\hline \multirow[t]{2}{*}{ Learning achievement indicator } & Indicator of satisfaction with learning environments \\
\hline & Indicator of citizen's learning improvement \\
\hline
\end{tabular}


Table 2 Demographic statistics

\begin{tabular}{llll}
\hline Measure & Category & Frequency & Percentage (\%) \\
\hline Gender & Male & 7681 & $56.50 \%$ \\
& Female & 5919 & $43.50 \%$ \\
Age (years) & Total & 13,600 & \\
& $18-35$ & 5892 & $43.40 \%$ \\
& $36-60$ & 6437 & $47.30 \%$ \\
& $61-70$ & 1271 & $9.30 \%$ \\
\hline
\end{tabular}

and learning approach $(r=0.68, p<0.01)$, while the correlation between learning engagement and learning achievement was relatively weak $(r=0.27, p<0.05)$. Positive correlations also existed among different evaluation indicators. For example, citizen reading was significantly correlated with learning approach $(r=0.64, p<0.01)$ and its three evaluation indicators, i.e., citizen's mobile learning $(r=0.59, p<0.01)$, selfregulated learning $(r=0.43, p<0.01)$, and utilization of city online learning platform $(r=0.56, p<0.01)$. Citizen reading was also significantly correlated with learning achievement $(r=0.42, p<0.01)$ and its two evaluation indicators, i.e., satisfaction with learning environments $(r=0.38, p<0.01)$, and learning improvement $(r=0.33, p<0.01)$.

\section{Correlations between indicators of citizen learning experiences and influence factors}

The correlations between three citizen learning experiences indicators and some influence factors were tested by Spearman rho statistics. In this paper, the influence factors mainly include a city's per capita GDP, city population density, and per capita consumption expenditure. And per capita consumption expenditure refers to the expenditure of culture, education and entertainment service of urban resident households.

Results showed that per capita GDP was weakly correlated with learning engagement (rho $=0.29, p<0.05)$, and was not significantly correlated with learning approach and learning achievement. The correlations between population density and three citizen learning experiences indicators, between per capita consumption expenditure and three citizen learning experiences indicators were all not significant.

\section{Gender difference and age difference of citizen learning experiences}

The method of crosstab analysis and chi-square statistics were adopted to investigate whether different groups of respondents categorized by gender and age can present various behaviors in terms of learning experiences respectively. Data were missing from respondents who did not answer these questions.

When asked if there were any staged learning objectives in 2015, over half (54.5\%) of all respondents gave positive answers.

Table 3 Summary descriptive statistics for indicators of citizen learning experiences

\begin{tabular}{lllllll}
\hline & $N$ & $M$ & $S D$ & CV & Min & Max \\
\hline Learning engagement & 68 & 0.70 & 0.09 & 0.14 & 0.51 & 0.98 \\
Learning approach & 68 & 0.64 & 0.12 & 0.20 & 0.36 & 1 \\
Learning achievement & 68 & 0.85 & 0.05 & 0.05 & 0.73 & 0.99 \\
\hline
\end{tabular}


Chi-square test indicated that males and females were not significantly different on whether or not they had set staged objectives $\left(x^{2}=0.763, d f=1, N=6669, p=0.383\right.$ ). Age groups of the respondents were associated with setting learning objectives $\left(x^{2}=292.694, d f=2, N=6669, p=0.000\right)$. It means that the proportion of persons who set learning objectives is decreasing with age. The proportion of 18-35 years old citizens who set learning objectives was $64.2 \%$. The proportion of 36-60 years old citizens who set learning objectives was $47.7 \%$. And the proportion of $61-70$ years old citizens who set learning objectives was only $28.5 \%$.

When inquired whether the surrounding learning environments could meet their learning needs, only $15.6 \%$ of responses chose "completely satisfied", while $22.6 \%$ of them chose "not satisfied". It indicates that the urban learning environments need some improvement.

Chi-square test revealed that a significant association was found between gender and degree of satisfaction with learning needs $\left(\chi^{2}=17.896, d f=2, N=6669, p=0.000\right)$. The proportion of males who thought the surrounding learning environments could completely satisfy their learning needs was $17.3 \%$, which was higher than that proportion of females (13.5\%). A significant association was found between age groups and degree of satisfaction with learning needs $\left(x^{2}=42.993, d f=4, N=6669, p=0.000\right)$. The proportion of persons in 18-35 years old group who believed that the surrounding learning environments could "completely satisfy" their learning needs was $12.6 \%$, which was significantly lower than that proportions of 36-60 years old group (18.5\%) and 6170 years old group (18.2\%).

When inquired if there was any great improvement in knowledge or skills through learning, $77.2 \%$ of the respondents thought there had been a great improvement. It indicates that the citizens can accept their learning achievement.

Chi-square test revealed that males and females were not significantly different on the learning achievement $\left(\chi^{2}=2.586, d f=3, N=6669, p=0.460\right)$. Age groups of the respondents was related to the perception of learning achievement $\left(x^{2}=33.780, d f=6, N=6669\right.$, $p=0.000)$. It means that the proportion of persons whose perception of learning achievement was "greatly" or "relatively great" was decreasing with age. The proportion of persons in 18-35 years old group whose perception of learning achievement was "greatly" or "relatively great" was $78.6 \%$, higher than other groups with $76.4 \%$ in $36-60$ years old group and $71.1 \%$ in $61-70$ years old group.

\section{Discussion and conclusions}

Citizen learning experiences can be understood as perceptions, reactions, and performances in learning environments. This study analyzes citizen learning experiences' features from the perspective of learning engagement, learning approach, and learning achievement.

From this study, we can conclude that citizens from different cities have different learning perceptions. Citizens from 68 cities have a similar learning perception on learning achievements while levels of citizens' perception on learning approach differ greatly. The three dimensions of learning experiences: learning engagement, learning approach, and learning achievement are correlated. Learning engagement strongly correlates with learning approach, and its link with learning achievement is relatively weak. 
Citizen reading is related to multiple evaluating indicators such as learning engagement, learning approach and learning achievement. It indicates that reading is an important activity for citizens' learning. In regard of the city's economic level, per capita GDP is weakly related to learning engagement. This shows that a city's economic development not only supports the city's infrastructure construction, but also to a certain extent provides a material basis for learning to help the citizens learn at any time, any place, any way, and at any pace.

The proportion of citizens with staged learning targets decreases with the increase of age. This indicates that citizens' self-management and study progress control may diminish with the increase of age. Male subjects are more satisfied with the surrounding learning environment, compared with female subjects. However, their perception of learning achievement does not differ greatly. Citizens' satisfaction with learning environments and learning achievement differ with age. Citizens in 18-35 years old group tend to be less satisfied with the lowest satisfaction rate, while the citizens in 61-70 years old group are opposite. The levels of citizens' satisfaction of the achievement of knowledge and skills by learning become lower with age.

Reaching the goal of sustainable development of smart learning environments and smart cities, governments need to optimize guiding policies on their top-level. Cities of different countries should explore new modes for the construction of smart learning environments. They should encourage citizens to put more time, money and effort into various lifelong learning activities, develop multiple learning styles in the learning process to improve learning effects.

\section{Building smart learning cities to promote sustainable social development}

Sustainable living can happen only if communities truly embrace it as part of daily culture. Community capacity, referred to the capacity of society and people's development, can be a vehicle for community cohesion, sustainability and self-reliant (Hawkes, 2001). More and more cities have put education and lifelong learning at the heart of their community development. To promote sustainable economic, social and environmental development, cities from Amman (Jordan) and Balange (the Philippines) to Bahir Dar (Ethiopia) and Ybycui (Paraguay) are transforming themselves into learning cities (UNESCO, 2016). China also proposed measures to develop new city, green city, smart city and civilian city. Smart city and smart learning environments can make learning more enjoyable, available and accessible for all citizens, and that will guide the sustainable social development.

\section{Developing library networks to increase learning opportunities}

Library networks in cities can promote social interaction and bring education and knowledge to marginalized communities. For example, the Spain Library, strategically located atop a hill, is a landmark conveying a message of public domain (Kimmelman, 2012). Curitiba, renowned as a highly planned city, is one of the leaders in green technology innovation. The education system was one of the key systems in the process of Curitiba's holistically urban transformation. Curitiba constructed lighthouse towers that both provided lookout facilities and incorporated new libraries, thus reinforced civic identity by providing beacons of knowledge and security (UNESCO, 2016). 
This study is a preliminary analysis of the characteristics of citizen learning experiences. In the future, we will focus on the possible reasons that cause such finding phenomena, and compare other factors and features that may influence citizen's learning experiences. Additionally, we may increase the research scope to amend the research questionnaire and further improve the feature analysis of citizens' learning experiences.

Authors' contributions

All authors read and approved the final manuscript.

Competing interests

The authors declare that they have no competing interests.

\section{Publisher's Note}

Springer Nature remains neutral with regard to jurisdictional claims in published maps and institutional affiliations.

\section{Author details}

${ }^{1}$ Smart Learning Institute of Beijing Normal University, No. 12 Xueyuan South Road, Haidian District, Beijing, China.

${ }^{2}$ State Information Center, No. 58, SanLiHe Road, Beijing, China.

Received: 29 May 2017 Accepted: 15 October 2017

Published online: 25 October 2017

\section{References}

A Datta, New urban utopias of postcolonial India: "Entrepreneurial urbanization" in Dholera smart city, Gujarat. Dialog. Hum. Geography 5(1), 3-22 (2015)

AA Elnaga, The impact of perception on work behavior. Kuwait Chapt. Arabian J. Busi. Manage. Rev 2(2), 56 (2012)

X Feng, Y Wu, Z Zhu, The design of smart learning experiences. Chin. Educ. Technol. 12, 14-19 (2013)

J Forlizzi, K Battarbee, Understanding Experience in Interactive Systems. In the Proceedings of DIS 2004 (ACM Press, Cambridge, 2004), pp. 261-268

RM Gagne, The Conditions of Learning and Theory of Instruction (Holt, Rinehart and Winston, New York, 1985)

M Hassenzahl, N Tractinsky, User experience-a research agenda. Behav. Inform. Technol. 25(2), 91-97 (2006)

$J$ Hawkes, The Fourth Pillar of Sustainability: culture's Essential Role in Public Planning (Common Ground, Melbourne, 2001)

Y Hu, Study on learning experiences of smart classroom for primary and middle school (Unpublished Doctoral Dissertation) (Beijing Normal University, Beijing, 2015)

R Huang, Y Hu, J Yang, in Ubiquitous Learning Environments and Technologies, ed. by Kinshuk, R Huang. Improving learner experience in the technology rich classrooms (Springer Berlin Heidelberg, Berlin, Heidelberg, 2015), pp. 243-258

R Huang, D Liu, L Fan, R Zhuang, H Fang, W Cheng, Y Jiao, White Paper: Smart Learning Environments in China 2015 (Smart Learning Institute of Beijing Normal University, Beijing, 2015) from http://pan.baidu.com/s/1hsk505Q

R Huang, D Liu, R Zhuang, 2016 Index Report of Smart Learning Environments in Chinese Cities (Smart Learning Institute of Beijing Normal University, Beijing, 2016) from http://pan.baidu.com/s/1jlDLTv4

R Huang, J Yang, Y Hu, From the digital learning environment to the smart learning environment: The change and trend of the learning environment. Open Educ. Res. 1, 75-84 (2012)

B Jia, E Xu, J Zhang, The summary of the research for learning performance development in China. E-educ. Res. 1, 53-58 (2013)

Kimmelman, M. (2012). A City Rises, along with its Hopes, the New York Times. Retrieved from http://www.nytimes. com/2012/05/20/arts/design/fighting-crime-with-architecture-in-medellin-colombia.html

KR Kunzmann, Urbanization in China: Learning from Europe? A European perspective. Int. J. Urban Sci. 19(2), 119-135 (2015)

Mahlke, S. (2005). Understanding users' experience of interaction. Paper presented at the Proceedings of the 2005 annual conference on European association of cognitive ergonomics. (University of Athens) pp. 251-254

Nat. Bureau Stat. People's Repub. Chin. (2016). China Statistical Yearbook 2016. Retrieved October 20, 2016, from http://www.stats.gov.cn/tjsj/ndsj/2016/indexeh.htm

Norman, D., Miller, J., \& Henderson, A. (1995). What you see, some of what in the future, and how we go about doing it: HI at Apple Computer. Proceedings of $\mathrm{CH}$ 1995, Denver

UNESCO. (2015a). Rethinking Education. Towards a global common good? Retrieved October 15, 2016, from http://www.unesco.org/fileadmin/MULTIMEDIA/FIELD/Cairo/images/RethinkingEducation.pdf

UNESCO. (2015b). UNESCO Global Network of Learning Cities. Retrieved November 18, 2016, from http//uil.unesco.org/fileadmin/ keydocuments/LifelongLearning/learning-cities/en-unesco-global-network-of-learning-cities-guiding-documents.pdf

UNESCO. (2016). Global Education Monitoring Report. Retrieved November 15, 2016, from http://en.unesco.org/gem-report/

United Nation General Assembly. (2015). Transforming our world: the 2030 Agenda for Sustainable Development. Retrieved December 25, 2016, from https://sustainabledevelopment.un.org/content/documents/21252030\%20 Agenda\%20for\%20Sustainable\%20Development\%20web.pdf

United Nations, Department of Economic and Social Affairs, Population Division (2015). World Urbanization Prospects: The 2014 Revision. Retrieved December 20, 2016, from https:/esa.un.org/unpd/wup/publications/files/ wup2014-highlights.Pdf

United Nations-Habitat. (2016). New urban agenda: Quito Declaration on Sustainable Cities and Human Settlements for All. Retrieved December 25, 2016, from http://citiscope.org/sites/default/files/h3/Habitat_IIINew_Urban_Agenda_ 10 September_2016.pdf

World Bank. (2016). World Bank Open Data. Retrieved September 16, 2016, from http://data.worldbank.org/. 